\title{
The effects of corpus luteum removal during gestation on parturition in the tammar wallaby (Macropus eugenii)
}

\author{
I. R. Young and Marilyn B. Renfree \\ School of Environmental and Life Sciences, Murdoch University, Western Australia, 6153
}

\begin{abstract}
Summary. Removal of the corpus luteum of pregnancy of the tammar wallaby interfered with successful parturition if carried out before Day 17 of the 27-day pregnancy. After removal at Days 17 and $21,40 \%$ of animals gave birth but pouch young died within $24 \mathrm{~h}$; if performed at Days 23 or 25 , pouch young survived. However, surgery also affected sham-operated controls if performed between Days 15 and 21. In control animals, sodium pentobarbitone followed by halothane anaesthesia was the least disruptive anaesthetic procedure. This study shows that the corpus luteum has an essential role in parturition and subsequent survival of the neonate in the pouch.
\end{abstract}

\section{Introduction}

The corpus luteum (CL) is necessary for early development in all mammalian species. Some, such as the goat and rabbit, retain this dependence throughout gestation, while others, such as the guinea-pig, sheep and man, can tolerate ovariectomy at some stage in gestation depending on the relative importance of the $\mathrm{CL}$ and placenta in supplying progesterone for maintenance of pregnancy (Davies \& Ryan, 1972).

In marsupials, ovariectomy after early pregnancy does not interrupt embryonic development but parturition fails. Hartman (1925) reported fetal death after ovariectomy at all stages of gestation in the American opossum (Didelphis virginiana) but re-evaluation of his data (Buchanan, 1969) and additional experimental evidence (Renfree, 1974) indicate that development continues if ovariectomy is performed after Day 6. Tyndale-Biscoe (1963) found that bilateral ovariectomy of the quokka (Setonix brachyurus) after Day 7 following removal of the pouch young (RPY) did not prevent the development of the embryo to normal term. At term the fetuses of ovariectomized quokkas were either retained in utero or expelled from the uterus without traversing the median vagina. After removal of the ovary bearing the CL during late pregnancy one animal gave birth and successfully suckled the neonate. Four other animals, similarly treated, and their controls all failed to give birth. Surgery at that stage of gestation was apparently a greater threat to fetal survival than ovariectomy.

In the tammar wallaby (Macropus eugenii) embryonic development is normal after bilateral ovariectomy on Day 8 after RPY but parturition fails (Tyndale-Biscoe, 1970). Normal term fetuses result from progesterone injection during seasonal quiescence, but the $\mathrm{CL}$ remains inactive: only 1 of 6 fetuses allowed to go to term was born alive (Renfree \& Tyndale-Biscoe 1973).

Sharman (1965) reported that 2 of 4 brush-tail possums (Trichosurus vulpecula) gave birth after CL removal on Day 11 of the $17 \frac{1}{2}$ day gestation period; earlier removal led to fetal death with evacuation from the uterus into the median vaginal cul-de-sac, while CL removal on Day 7 followed by 2-3 days of progesterone injections allowed young to develop to term. 
The evidence therefore suggests that the CL (or some other ovarian tissue in the quokka and tammar) does play a part in the process of parturition in marsupials, and that its presence is necessary up to a certain stage of gestation, after which the $\mathrm{CL}$ or ovary becomes dispensible. This study of the tammar wallaby was conducted to determine the importance of the CL in parturition and the period of gestation during which it exerts its effect.

\section{Materials and Methods}

The study extended over the breeding seasons of 1976, 1977 and 1978. Different anaesthetic procedures were used in each year in order to minimize the inimical effects of surgery (see Table 2). The regimen used in 1978 is now used routinely.

Animals were kept in fenced yards, after removal of pouch young to initiate development of diapause blastocysts. The animals were removed from the yards on the day of surgery and laparotomies were performed under aseptic conditions as described previously (Renfree \& Tyndale-Biscoe, 1978). The CL of pregnancy was removed by incising the theca with iris scissors and enucleating the luteal tissue. Powdered thrombin (Parke-Davis) was applied to the site to control haemorrhage.

Control animals were subjected to laparotomy and the ovary bearing the CL of pregnancy was held with forceps for the same length of time as was required for luteal excision in the experimental animals, and then replaced intact.

After surgery animals were returned to their enclosures within 1 week (up to Day 23 after RPY) or immediately after recovery from anaesthesia (Days 23 and 25). It was intended that all animals should spend the immediate pre-partum period free of human disturbance to minimize abnormal maternal behaviour. In our colony, birth normally occurs on Day 27 (Table 1).

Table 1. Mean \pm s.d. duration of gestation after removal of pouch young in the tammar wallaby

\begin{tabular}{lcc}
\hline \multicolumn{1}{c}{ Source } & $\begin{array}{c}\text { No. of } \\
\text { animals }\end{array}$ & $\begin{array}{c}\text { Gestation length } \\
\text { (days) }\end{array}$ \\
\hline $\begin{array}{c}\text { Berger (1970) } \\
\text { Tyndale-Biscoe \& } \\
\text { Rodger (1978) }\end{array}$ & 14 & $27.5 \pm 0.7$ \\
$\begin{array}{c}\text { Merchant (1979) } \\
\text { Murdoch Colony } \\
\text { (present work) }\end{array}$ & 11 & $27.6 \pm 1.2$ \\
\hline
\end{tabular}

Animals were caught and their pouches inspected for pouch young on Day 27, then daily up to Days 30-32. Animals failing to produce pouch young in 1976 and 1977 were subjected to laparotomy and the genital tracts were examined for the presence of fetuses in the uterus or vaginal complex as far posteriorly as the opening of the bladder. Such laparotomies were not performed in 1978 .

Anaesthesia and surgery had a detrimental effect on survival of fetuses when carried out between Days 13 and 21 (Tables 2 and 3). The best success was obtained using sodium pentobarbitone followed by halothane (Table 2 ).

\section{Results}

The CL were removed from a total of 39 animals at various stages from Day 6 after RPY to Day 25 after RPY and 31 controls underwent sham operations (Table 3). 
Up to Day 15

After CL removal on Days 6 to 15 no fetuses survived, whereas $9 / 15$ control animals gave birth and the young survived in the pouch. All but 5 of the experimental and control animals which failed to produce pouch young in 1976 and 1977 showed empty, post-partum uteri and empty anterior vaginal complexes. These 5 animals ( 2 control, 3 experimental) had no CL of pregnancy and the uteri did not have a post-partum appearance; they were therefore diagnosed as non-pregnant. These animals should have been excluded from the results at the time of surgery but pregnancy is difficult to diagnose before Day 15 when these were subjected to operation.

\section{Days 17 and 21}

After CL removal on Days 17 and $21,4 / 10$ fetuses reached the pouch but all died within 24 $\mathrm{h}$ of birth. Only $3 / 8$ sham-operated animals produced pouch young but all survived in the pouch. All animals failing to produce pouch young that were laparotomized at Days 31-33 showed post-partum uteri.

Table 2. Anaesthetic agents used for surgery of tammar wallabies at specific gestational age in each year, and numbers of control animals giving birth

\begin{tabular}{cccc}
\hline $\begin{array}{c}\text { Day of } \\
\text { operation }\end{array}$ & 1976 & 1977 & 1978 \\
\hline 6 & & $2 / 3 \dagger$ & $1 / 1 \S$ \\
10 & & $3 / 3 \dagger$ & $1 / 1 \S$ \\
13 & & $1 / 3 \ddagger$ & \\
15 & & $1 / 3 \ddagger$ & $0 / 1 \S$ \\
17 & $0 / 1^{*}$ & & $1 / 3 \S$ \\
21 & $0 / 1^{*}$ & & $2 / 3 \S$ \\
23 & $0 / 1^{*}$ & & $3 / 3 \S$ \\
25 & $0 / 1^{*}$ & & $3 / 3 \S$ \\
\hline
\end{tabular}

* Sodium thiamylal (Surital: Parke-Davis. Detroit, Michigan): $2 \frac{1}{2} \% \quad(w / v), \quad 8-10$ $\mathrm{ml} /$ animal.

$\dagger$ Halothane (Fluothane: I.C.I., Villawood, N.S.W., 2163, Australia) in oxygen.

$\ddagger$ Alphaxalone: Alphadolone (Saffan: Glaxo, U.K.): $2 \mathrm{ml} /$ animal plus halothane in oxygen.

$\S$ Pentobarbitone sodium (Bulk powder: May and Baker, Dagenham, U.K.) made up as $6 \%$ solution in $0.9 \% \mathrm{NaCl}: 2 \mathrm{ml}$ of 60 $\mathrm{mg} / \mathrm{ml} /$ animal plus halothane in oxygen.

Day 23

After operation at this time $1 / 5$ experimental and $3 / 4$ control animals gave birth. All the pouch young survived. No fetuses were observed trapped in the lateral vaginae at laparotomy, although as before the uteri were enlarged and had apparently carried a fetus to term.

Day 25

Successful births occurred in $2 / 5$ experimental animals and all pouch young survived. The success rate was higher $(2 / 3)$ in 1978 than in $1976(0 / 2)$ and could reflect improved anaesthetic and/or surgical technique.

Of the control animals, $3 / 4$ gave birth, and the pouch young survived. The 1 control and 2 experimental animals which failed to give birth in 1976 had empty, enlarged uteri and vaginae at laparotomy. 
Table 3. The numbers (\%) of experimental (E) and control (C) tammar wallabies giving birth after surgery at specific gestational ages

\begin{tabular}{|c|c|c|c|c|c|c|c|c|}
\hline \multirow{2}{*}{$\begin{array}{l}\text { Day of } \\
\text { operation }\end{array}$} & \multicolumn{2}{|c|}{1976} & \multicolumn{2}{|c|}{1977} & \multicolumn{2}{|c|}{1978} & \multicolumn{2}{|c|}{ Totals (\%) } \\
\hline & E & $\mathrm{C}$ & E & $\mathrm{C}$ & E & $\mathrm{C}$ & $\mathrm{E}$ & $\mathrm{C}$ \\
\hline 6 & & & $0 / 2$ & $2 / 3$ & $0 / 2$ & $1 / 1$ & $0 / 4(0)$ & $3 / 4(75)$ \\
\hline 10 & & & $0 / 3$ & $3 / 3$ & $0 / 2$ & $1 / 1$ & $0 / 5(0)$ & $4 / 4(100)$ \\
\hline 13 & & & $0 / 3$ & $1 / 3$ & $0 / 2$ & & $0 / 5(0)$ & $1 / 3$ \\
\hline 15 & & & $0 / 3$ & $1 / 3$ & $0 / 2$ & $0 / 1$ & $0 / 5(0)$ & $1 / 4 \quad(25)$ \\
\hline Sub-totals & & & $0 / 11$ & $7 / 12$ & $0 / 8$ & $2 / 3$ & $0 / 19(0)$ & $9 / 15(60)$ \\
\hline 17 & $1 / 2$ & $0 / 1$ & & & $1 / 3$ & $1 / 3$ & $2 / 5(40)$ & $1 / 4 \quad(25)$ \\
\hline 21 & $0 / 2$ & $0 / 1$ & & & $2 / 3$ & $2 / 3$ & $2 / 5(40)$ & $2 / 4(50)$ \\
\hline 23 & $1 / 2$ & $0 / 1$ & & & $0 / 3$ & $3 / 3$ & $1 / 5(20)$ & $3 / 4(75)$ \\
\hline 25 & $0 / 2$ & $0 / 1$ & & & $2 / 3$ & $3 / 3$ & $2 / 5(40)$ & $3 / 4 \quad(75)$ \\
\hline Sub-totals & $2 / 8$ & $0 / 4$ & & & $5 / 12$ & $9 / 12$ & $7 / 20(35)$ & $9 / 16(56)$ \\
\hline
\end{tabular}

\section{Discussion}

Although the CL of the tammar is essential for only a brief period to permit embryonic development (Tyndale-Biscoe, 1979) this study confirms that it is necessary for a much longer period, at least up to Day 17 and perhaps to Day 21 if successful parturition is to occur.

Ovariectomy in rats leads to fetal crushing and abortion, apparently as a result of progesterone withdrawal and consequent myometrial activity (Amoroso \& Finn, 1962). In other species (e.g. rabbit, guinea-pig, man) ovariectomy at a susceptible stage of pregnancy causes abortion relatively promptly (Amoroso \& Finn, 1962; Heap \& Deanesly, 1966). The tammar wallaby, quokka, brush-tail possum and opossum differ from these species in that pregnancy continues even in the absence of functional CL although parturition is inhibited (Hartman, 1925; Tyndale-Biscoe, 1963, 1970; Renfree \& Tyndale-Biscoe, 1973; Renfree, 1974).

In the tammar, ovariectomy at or before Day 6 may cause early embryonic mortality by preventing the development of a luteal-phase endometrium by the CL secretions (Renfree, 1973; Tyndale-Biscoe, Hearn \& Renfree, 1974; Tyndale-Biscoe, 1979). By Day 6-8, however, the luteal phase is established and the $C L$ is dispensible for continued embryonic development (Tyndale-Biscoe, 1970; Renfree \& Tyndale-Biscoe, 1973). Lemon (1972), working with tammars, confirmed fetal survival after ovariectomy (animals killed at Day 25) and CL removal (animals killed at Day 22) at Day 10 after RPY. In this study because all animals without pouch young had one uterus showing a characteristic post-partum appearance, identical to that described in the tammar by Tyndale-Biscoe \& Rodger (1978), it was assumed that the failure to recover pouch young from animals lutectomized on Days 10,13 and 15 was due to fetal loss around the expected time of parturition and not due to failure of embryos to continue development. Had embryos died before Day 16 the uterus would not have had this appearance. Furthermore, resorption of fetuses occurs slowly in the tammar and they may be found up to 10 days after the expected time of birth. No such resorbed fetuses were found.

If this assumption is valid, the results suggest that the $\mathrm{CL}$ of the tammar elaborates a substance essential for successful parturition at least up to or on Day 16. The CL achieves its greatest size and weight at around Day 15 shortly before definitive attachment by the yolk sac placenta occurs, and contains considerable amounts of progesterone (Renfree \& Tyndale-Biscoe, 1973). Progesterone and relaxin are probably both involved in loosening the vaginal complex in marsupials (Tyndale-Biscoe, 1966, 1969; Tyndale-Biscoe et al., 1974). Relaxin has been measured in the CL of the tammar wallaby, reaching maximal concentrations at Day 17 and 
with appreciable amounts remaining at Day 25 (C. H. Tyndale-Biscoe, personal communication). Without vaginal loosening, the fetus could be damaged by pressure during transport.

It is possible that the mechanism of parturition in the tammars lutectomized on Days 10,13 and 15 was normal, but that the neonate was incapable of transferring itself to the pouch because of failure of some maturational event, but this seems less likely. Some fetuses reached the pouch after CL removal at Days 17 and 21 of gestation, which suggests that by the time of implantation the $\mathrm{CL}$ is no longer essential and that it has produced sufficient secretion to allow parturition to occur in some animals. However, all the young which did reach the pouch died soon after, usually within $24 \mathrm{~h}$. If the secretions of the CL are required for the initiation of lactation, the young may have died because of lactation failure. It is also possible that the vaginal canal was left inadequately prepared by the cessation of $\mathrm{CL}$ secretions, ultimately resulting in fetal damage during birth and death after reaching the pouch.

Although only $4 / 10$ of the animals operated at Days 17 and 21 achieved successful parturition, some allowance must be made for the controls. Between Days 13 and 21, surgery itself has a marked effect on the control animals, with only $5 / 15$ giving birth, compared to $7 / 8$ before this time and $6 / 8$ after. This is a result similar to that obtained in quokkas subjected to pentobarbitone sodium anaesthesia (Tyndale-Biscoe, 1963) and implies that surgery during the attachment stage could interfere with the attachment of the placenta, or with the endometrium and its secretions, or inhibit CL function in some way. Relative to controls, the proportion of successful births among animals lutectomized on Days 23 and 25 was low, but normal parturition and neonatal survival did occur. The success rate may reflect some continued inhibition or interference caused by anaesthesia and surgery. However, it does appear that the CL has exerted sufficient influence on both the reproductive tract and the mammary gland by this stage to allow the birth of a viable fetus which survives in the pouch.

The essential role of the $\mathrm{CL}$ in the physiology of parturition could be solely due to the influence of relaxin and progesterone. The results of Sharman (1965) and Tyndale-Biscoe (1966) suggest that progesterone can substitute for the CL in the brush-tail possum, and in the tammar wallaby progesterone levels remain high until Day 22-23 in the peripheral plasma (Lemon, 1972) and the CL. Relaxin is present in the CL of the tammar wallaby and induced birth in 2 of 9 spayed quokkas. The remaining quokkas had live retained fetuses (3) or abnormal fetal development (4) (Tyndale-Biscoe, 1963; personal communication). Oestrogens could be involved because, although peripheral levels are extremely low at Day 25 (Renfree \& Heap, 1977), the occurrence of a post-partum oestrus in the tammar suggests that higher levels could be circulating in the utero-ovarian blood at parturition. However, Tyndale-Biscoe et al. (1974) point out that parturition can occur in other macropodid species without the need for a postpartum oestrus and this detracts from the likelihood that elevated oestrogen levels are needed for birth to occur. Since a follicular contribution is probably not necessary for parturition, it could be surmised that luteal oestrogen production is also unnecessary. However, removal of the CL causes return to oestrus and ovulation 12 days later, regardless of the day of operation during the cycle (Tyndale-Biscoe \& Hawkins, 1977), and so the possible role of oestrogen in the present results cannot be excluded.

We thank Mr Stuart Green for assistance, and Dr C. H. Tyndale-Biscoe for helpful comments on the manuscript and for permission to quote unpublished results. This study was supported by grants from the ARGC (DI-15759) and NIH (HD-09387). I.R.Y. was supported by a Commonwealth Postgraduate Research Award.

\section{References}

Amoroso, E.C. \& Finn, C.A. (1962) Ovarian activity during gestation, ovum transport and implantation. In The Ovary, 1st edn, Vol. 1, pp. 451-537. Ed. S. Zuckerman. Academic Press, New York.
Berger, P. (1970) The reproductive biology of the tammar wallaby, Macropus eugenii, Desmarest. Ph.D. thesis, Tulane University.

Buchanan, G.D. (1969) Reproduction in the ferret 
(Mustela furo). II. Changes following ovariectomy during early pregnancy. $J$. Reprod. Fert. 18, 305316.

Davies, J.J. \& Ryan, K.J. (1972) Comparative endocrinology of gestation. Vitams Horm. 30, 223-278.

Hartman, C.G. (1925) The interruption of pregnancy by ovariectomy in the aplacental opossum: a study in the physiology of implantation. Am. J. Physiol. 71, 436-454.

Heap, R.B. \& Deanesly, R. (1966) Progesterone in systemic blood and placentae of intact and ovariectomized pregnant guinea-pigs. J. Endocr. 34, 417423.

Lemon, M. (1972) Peripheral plasma progesterone during pregnancy and the oestrous cycle in the tammar wallaby, Macropus eugenii. J. Endocr. 55, 63-71.

Merchant, J.C. (1979) The effect of pregnancy on the interval between one oestrus and the next in the tammar wallaby, Macropus eugenii. J. Reprod. Fert. 56 (in press).

Renfree, M.B. (1973) Proteins in the uterine secretions of the marsupial Macropus eugenii. Devl Biol. 32, 4149.

Renfree, M.B. (1974) Ovariectomy during gestation in the American opossum Didelphis marsupialis virginiana. J. Reprod. Fert. 39, 127-130.

Renfree, M.B. \& Heap, R.B. (1977) Steroid metabolism in the placenta, corpus luteum and endometrium during pregnancy in the marsupial Macropus eugenii. Theriogenology 8, 164.

Renfree, M.B. \& Tyndale-Biscoe, C.H. (1973) Intrauterine development after diapause in the marsupial Macropus eugenii. Devl Biol. 32, 28-40.

Renfree, M.B. \& Tyndale-Biscoe, C.H. (1978) Manipulation of marsupial embryos and pouch young. In Methods in Mammalian Reproduction, pp.
307-331. Ed. J. C. Daniel. Academic Press, New York.

Sharman, G.B. (1965) The effects of the suckling stimulus and oxytocin injection on the corpus luteum of delayed implantation in the red kangaroo. Proc. 2nd Int. Congr. Endocr., London, pp. 669-674. Ed. S. Taylor. Excerpta Medica Foundation (Int. Congr. Ser. No. 83), Amsterdam.

Tyndale-Biscoe, C.H. (1963) Effects of ovariectomy in the marsupial Setonix brachyurus. J. Reprod. Fert. 6, $25-40$.

Tyndale-Biscoe, C.H. (1966) The marsupial birth canal. Symp. zool. Soc. Lond. 15, 233-250.

Tyndale-Biscoe, C.H. (1969) Relaxin activity during the oestrous cycle of the marsupial Trichosurus vulpecula (Kerr). J. Reprod. Fert. 19, 191-193.

Tyndale-Biscoe, C.H. (1970) Resumption of development by quiescent blastocysts transferred to primed, ovariectomised recipients in the marsupial, Macropus eugenii. J. Reprod. Fert. 23, 25-32.

Tyndale-Biscoe, C.H. (1979) Hormonal control of embryonic diapause and reactivation in the tammar wallaby. In Maternal Recognition of Pregnancy, Ciba Fdn Symp. Ed. J. Whelan. Elsevier-North Holland, Amsterdam. (in press).

Tyndale-Biscoe, C.H. \& Hawkins, J. (1977) The corpora lutea of marsupials: aspects of function and control. In Reproduction and Evolution, pp. 245-252. Eds. J. H. Calaby \& C. H. Tyndale-Biscoe. Australian Academy of Science, Canberra.

Tyndale-Biscoe, C.H. \& Rodger, J.C. (1978) Differential transport of spermatozoa into the two sides of the genital tract of a monovular marsupial, the tammar wallaby (Macropus eugenii). J. Reprod. Fert. 52, 3743.

Tyndale-Biscoe, C.H., Hearn, J.P., \& Renfree, M.B. (1974) Control of reproduction in macropodid marsupials. J. Endocr. 63, 589-614.

Received 2 October 1978 